\title{
The Private Universe
}

A s I type this, the debate rages on whether the BlackBerry service will cease to exist as we know it. As of press time, a judge had refused to issue an order of injunction against BlackBerry maker RIM (Research in Motion) in its ongoing patent infringement battle with NTP Inc., giving users at least another 30 days to feed their addiction.

If BlackBerry goes down, employees in millions of corporations will have nothing to fiddle with between the office and the home. The train ride into the city might actually become-gasp-a social event once more.

$\mathrm{Me}$ ? I'm not one to throw stones-my glass house is a Danger Sidekick. I rely on it for my always-on connection. The difference, however, is I use my Sidekick for social communication, not for business purposes.

Regardless, the personal communication revolution is an everyday occurrence. It's now an oddity if one can't be reached when out of the office. The double-edged sword is that it allows us to work anywhere, at any time. There goes the weekend and the family vacation as we know it.

It has been a natural progression for the category of technological devices known as purpose-built systems, although that name in itself is a misnomer. Embedded computers in automobiles have migrated to home appliances, which spurred the smart home revolution. In parallel, cellular phones added cameras, games, calendars, e-mail, and an operating system, such that there is no such thing as "just a cellphone" anymore. It has gotten to the point where I am hard pressed to immediately come up with any device that goes by the moniker "purposebuilt" honestly. Even pacemakers, which were created to regulate a person's heartbeat, now have the ability to e-mail anomalies to the wearer's physician on demand.

All this capability takes a lot of programming, which takes a certain talent when working with small devices with big tasks. As a result, failure rates among these so-called purpose-built systems-smart phones being the best example-are on the increase. A recent Gartner report noted that enterprises today budget for at least a 20 percent loss or failure rate for PDAs. Even my beloved Sidekick, after only a year of use, is beginning to show signs of wear on the screen and occasional digital blips as

\author{
Reliability is A \\ BIG VIRTUE IN THE \\ BRAVE NEW WORLD \\ OF SMALL DEVICES
}

I'm inputting information.

Could standards help

improve the rate of failure?

Maybe so. But as much as

I recognize the importance

of standardizing technology, it goes against the grain of truly innovative ideas. The problem lies not in the technology itself but in the commoditization of such technology. As these tiny little computers become more popular, more are being made, and the corporations producing them will continue to look for ways to bring down the cost per unit.

Developing with the device's multitasking capabilities in mind, rather than trying to integrate multiple capabilities in a finished product, might help reduce the failure rates. And that can be tricky, time-consuming, and expensive. I know of few corporations that would have the patience for that combination for very long.

Take a look in this month's issue and you'll find a bevy of articles geared specifically to the problems of building a purpose-built system. Hopefully they'll spur designers and developers to think deeper and, by doing so, help reduce the failure rate of these devices. I don't know about you, but I want my Sidekick to be as trusty as Tonto was to the Lone Ranger.

ACM Queue board member and independent consultant Terry Coatta hits the nail right on the head in this month's issue when he writes, "While consumers will demand a broader set of functionality from devices, care needs to be taken in ensuring that these do not detract from the purpose of the device." So true. Some functionality in multipurpose devices just isn't that useful, such as the address book feature of the iPod (honestly, does anyone really use it?), and I'm sure I'm not alone when I say it's worth much more to me to have a single-purpose device that works well than to have a multipurpose device that works so-so. $Q$

CHARLENE O'HANLON, editor and publisher of ACM Queue, is mad about personal devices, but isn't as wild about the social networking phenomenon-how can anyone have 9,000 friends on MySpace.com??? 